\title{
Adjuvant psychological therapy for patients with cancer: a prospective randomised trial
}

Steven Greer, Stirling Moorey, John D R Baruch, Maggie Watson, Bernadette M Robertson,

Anne Mason, Linda Rowden, Matthew G Law, Judith M Bliss

\section{Abstract}

Objective-To determine the effect of adjuvant psychological therapy on the quality of life of patients with cancer.

Design-Prospective randomised controlled trial comparing the quality of life of patients receiving psychological therapy with that of patients receiving no therapy, measured before therapy, at eight weeks, and at four months of follow up.

Setting-CRC Psychological Medicine Group of Royal Marsden Hospital.

Patients-174 patients aged 18-74 attending hospital with a confirmed diagnosis of malignant disease, a life expectancy of at least 12 months, or scores on various measures of psychological morbidity above previously defined cut off points.

Intervention-Adjuvant psychological therapy, a brief, problem focused, cognitive-behavioural treatment programme specifically designed for the needs of individual cancer patients.

Main outcome measures-Hospital anxiety and depression scale, mental adjustment to cancer scale, Rotterdam symptom checklist, psychosocial adjustment to illness scale.

Results-156 (90\%) patients completed the eight week trial; follow up data at four months were obtained for 137 patients (79\%). At eight weeks, patients receiving therapy had significantly higher scores than control patients on fighting spirit and significantly lower scores on helplessness, anxious preoccupation, and fatalism; anxiety; psychological symptoms; and on orientation towards health care. These differences indicated improvement in each case. At four months, patients receiving therapy had significantly lower scores than controls on anxiety psychological symptoms; and psychological distress. Clinically, the proportion of severely anxious patients dropped from $46 \%$ at baseline to $20 \%$ at eight weeks and $20 \%$ at four months in the therapy group and from $48 \%$ to $41 \%$ and to $43 \%$ respectively among controls. The proportion of patients with depression was $40 \%$ at baseline, $13 \%$ at eight weeks, and $18 \%$ at four months in the therapy group and $30 \%, 29 \%$, and $23 \%$ respectively in controls.

Conclusions-Adjuvant psychological therapy produces significant improvement in various measures of psychological distress among cancer patients. The effect of therapy observed at eight weeks persists in some but not all measures at four month follow up.

Section of Epidemiology, Institute of Cancer Research, Sutton, Surrey SM2 5PT

Matthew G Law, Msc, statistician

Judith M Bliss, MSC, statistician

Correspondence to: Dr Greer.

BMF 1992;304:675-80 and physical wellbeing (that is, the life) of patients. Various psychotherapeutic proce that aim to alleviate psychological morbidity have been tested in randomised controlled studies. ${ }^{2-9}$ Most of these clinical trials were limited to patients with breast cancer. Six of the studies reported significant improvement in psychiatric symptoms or social adjustment, or both, but two studies showed no improvement. Differences in stage of disease, type of psychological treatment, and outcome measures preclude any general conclusions.

In view of formidable methodological problems in this area, it is useful to outline major requirements that should be met in clinical trials of psychotherapy for patients with cancer. Firstly, ethical issues must be considered: in particular, whether a control group not given therapy is justified and, if so, what provisions can be made for patients in the control group who require psychiatric treatment because they are suicidal or suffer from major psychiatric illness. Secondly, since the terms counselling and psychotherapy are vague headings encompassing a wide variety of activities, it is important to describe as fully as possible the kind of therapy that is being evaluated. Thirdly, measures of outcome should be based on systematically developed questionnaires of known reliability and validity; moreover, such questionnaires should be standardised for cancer patients. Caution should be exercised in applying questionnaires developed for psychiatric patients to cancer patients. This caveat applies particularly to the measurement of depression. The use of scales that contain somatic items such as fatigue and weight loss may be misleading because these can be symptoms of cancer or its treatment as well as of depression. Fourthly, data about the type and stage of disease and about the treatment for cancer should be obtained. Lastly, patients should be randomly assigned to psychological treatment groups and no treatment control groups or to different treatment groups. We have adopted these criteria in the present study.

The aim of the present study is to determine the effect of adjuvant psychological therapy, a treatment programme we have developed, on the quality of life of patients with cancer.

\section{Patients and methods}

The study sample comprised a consecutive series of patients attending the Royal Marsden Hospital. The selection criteria were any form of cancer except cerebral tumours and non-melanoma skin cancers; a life expectancy (as judged by clinicians) of at least 12 months; age 18-74; no obvious intellectual impairment, psychotic illness, or serious suicide risk; residence within $65 \mathrm{~km}$ of the hospital. Four to 12 weeks after primary diagnosis or first recurrence of cancer, patients were asked to complete two questionnaires: the hospital anxiety and depression scale ${ }^{10}$ and the mental adjustment to cancer scale, ${ }^{11 ! 2}$ which measures four broad dimensions of adjustment: fighting spirit, helplessness, anxious preoccupation, and fatalism. A pilot study of 79 cancer patients attending the same hospital, in which distributions of scores on these scales had been examined, allowed an operational definition of psychological morbidity to be given as scores of either $\geqslant 10$ on anxiety or $\geqslant 8$ on depression or both $\geqslant 12$ on helplessness and $\leqslant 47$ on fighting spirit. In patients with 
anxiety, depression, and helplessness these criteria represented one standard deviation above the mean; in the case of fighting spirit, one standard deviation below the mean.

Patients whose scores on screening revealed psychological morbidity as defined above were invited to participate in the randomised trial comparing adjuvant psychological therapy with no therapy. Patients giving their informed consent were randomly allocated to either therapy or no therapy by telephone randomisation organised by an independent statistician.

Patients not showing evidence of psychological morbidity were screened again with the hospital anxiety and depression and mental adjustment to cancer scales 12 months later. Those whose scores indicated psychological morbidity at that time were invited to participate in the trial.

Assessments of outcome for patients entering the trial were the hospital anxiety and depression ${ }^{10}$ and mental adjustment to cancer ${ }^{11}{ }_{12}^{12}$ scales; the psychosocial adjustment to illness scale, ${ }^{13}$ which measures health care orientation, work adjustment, domestic environment, sexual relationships, extended family relationships, the social environment, and psychological distress; and the Rotterdam symptom checklist, ${ }^{14}$ which measures quality of life in terms of physical as well as psychological symptoms. These questionnaires were completed by patients, supervised by members of the research group not involved in therapy, immediately before randomisation (baseline) and at eight weeks, four months, and one year after randomisation. Patients completed the assessment before randomisation and consequently had no knowledge of their allocated treatment groups.

Adjuvant psychological therapy is a cognitivebehavioural treatment programme developed jointly at the Royal Marsden Hospital and Institute of Cancer Research specifically for cancer patients. Therapy is conducted with individual patients and, where appropriate, their spouses; about six sessions, each lasting at least one hour, are held. Therapy focuses on the personal meaning of cancer to the individual and on the patient's coping strategies-that is, what the patient thinks and does to reduce the threat posed by cancer. Therapy is directed at current problems as defined jointly by the patient and the therapist. Among the cognitive and behavioural techniques used are identifying the patient's personal strengths and fostering these as a means of raising self esteem, overcoming feelings of helplessness, and promoting a fighting spirit; teaching patients to identify negative automatic thoughts underlying their anxiety and depression and how to challenge such thoughts; showing patients how to use imagination and role play as means of coping with impending stressful events; encouraging patients to carry out activities that give a sense of both achievement and pleasure so that patients can regain some control over their lives; encouraging expression of feelings and open communication between patient and spouse; and teaching progressive muscular relaxation to enable patients to control severe anxiety.

TABLE I-Mean (SD) scores at baseline of patients in trial of adjuvant psychological therapy and patients lost to after randomisation

\begin{tabular}{|c|c|c|c|c|}
\hline & \multicolumn{2}{|c|}{ Followed up } & \multicolumn{2}{|c|}{ Lost before eight week follow up } \\
\hline & $\begin{array}{l}\text { Therapy } \\
(\mathrm{n}=72)\end{array}$ & $\begin{array}{l}\text { Control } \\
(\mathrm{n}=84)\end{array}$ & $\begin{array}{l}\text { Therapy } \\
(n=13)\end{array}$ & $\begin{array}{c}\text { Control } \\
(\mathbf{n}=5)\end{array}$ \\
\hline \multicolumn{5}{|c|}{ Mental adjustment to cancer scale: } \\
\hline Fighting spirit & $47 \cdot 8(6 \cdot 0)$ & $47 \cdot 8(6 \cdot 6)$ & $44 \cdot 7(6 \cdot 1)$ & $47 \cdot 2(3 \cdot 4)$ \\
\hline Helplessness & $11 \cdot 2(3 \cdot 2)$ & $11 \cdot 3(3 \cdot 2)$ & $12 \cdot 2(2 \cdot 3)$ & $13 \cdot 8(2 \cdot 3)$ \\
\hline Anxious preoccupation & $23 \cdot 5(3 \cdot 2)$ & $23 \cdot 6(4 \cdot 3)$ & $22 \cdot 2(1 \cdot 9)$ & $24 \cdot 4(2 \cdot 1)$ \\
\hline Fatalism & $18 \cdot 8(3 \cdot 0)$ & $18.9(3.6)$ & $20 \cdot 2(2 \cdot 6)$ & $21 \cdot 0(2 \cdot 1)$ \\
\hline \multicolumn{5}{|c|}{ Hospital anxiety and depression scale: } \\
\hline Anxiety & $8 \cdot 6(3 \cdot 9)$ & $9 \cdot 2(4 \cdot 6)$ & $7 \cdot 9(3 \cdot 8)$ & $11 \cdot 4(6 \cdot 5)$ \\
\hline Depression & $6 \cdot 2(4 \cdot 0)$ & $5 \cdot 8(3 \cdot 5)$ & $6 \cdot 8(4 \cdot 9)$ & $8 \cdot 4(4 \cdot 8)$ \\
\hline
\end{tabular}

This treatment programme was developed in the year before the randomised trial. Weekly audiotaped sessions with patients outside the trial were used for training. A detailed description of adjuvant psychological therapy as well as the results of an early trial have been published. ${ }^{15} 16$ Therapy in the trial was conducted by SG, SM, and JDRB.

\section{STATISTICAL ANALYSIS}

Treatment comparisons were performed on the intent to treat principle, whereby all eligible patients (with data) are analysed according to randomised treatment, irrespective of the treatment they actually received.

When subscale scores were calculated, if a single item was missing on a given subscale then the score for that subscale was simply scaled up. If two or more items were missing then the subscale score was put to missing. Less than $8 \%$ of patients had missing scores on the hospital anxiety and depression and mental adjustment to cancer scales, but on the psychosocial adjustment to illness scale there was a greater proportion of missed scores, reaching $35 \%$ for the total score.

Subscale scores were analysed separately at two and four months. The analysis presented in table IV compares treatments, using the change in scores from baseline values immediately before randomisation. Confidence intervals for the treatment effect were based on the $t$ distribution. $\mathrm{p}$ Values were computed using the non-parametric Mann-Whitney test. No adjustment was made to $p$ values or confidence intervals to allow for the multiple comparisons performed. Analysis of covariance was used to investigate the possibility of different responses to therapy in subgroups defined by sex, age (split at median), stage of disease, and concurrent chemotherapy. Numbers of patients receiving antidepressants were very small and could not affect the results.

\section{Results}

The 12 month follow up is still in progress. In the present paper, we report results regarding the efficacy of therapy at eight weeks and four months of follow up.

A total of 1260 patients were screened initially using the hospital anxiety and depression scale and mental adjustment to cancer scale. Of these patients 293 (23\%) were found to be high scorers according to the criteria outlined above (including seven initially low scorers who became high scorers at the 12 month follow up) and were invited to take part in the study. A total of 96 patients (33\%) refused, and $23(8 \%)$ could not be randomised for other reasons (too ill, lost contact, etc). The remaining 174 patients were randomised. Eighteen of these patients (13 psychotherapy, five control) were lost to the study for the following reasons: three died before the eight week assessment, three had become too ill to be assessed, four refused; in one case follow up was omitted at the general practitioner's request; and seven patients had either moved away or could not be traced. Comparison of baseline scores between these 18 patients and the 156 who were assessed at eight weeks or four months of follow up revealed no substantial differences (table I). Outcome data were obtained in 153 patients at eight weeks (three additional patients could not be assessed, because of their medical state, until four months) and 137 patients at four months.

Patients who refused to enter the trial were similar to those who took part in terms of marital status, diagnosis (breast cancer $v$ other cancer), stage of disease, performance status, and scores on depression and helplessness. There were some significant differences, however: refusers were older (mean age $56.3 v 51.5$ years; $p=0.002$ ) and contained a lower proportion of 
TABLE II-Characteristics of patients completing trial of adjuvant psychological therapy. Values are numbers (percentages) unless otherwise stated

\begin{tabular}{|c|c|c|c|c|}
\hline & $\begin{array}{l}\text { Therapy group } \\
\quad(n=72)\end{array}$ & $\begin{array}{l}\text { Control group } \\
\quad(n=84)\end{array}$ & $\begin{array}{c}\text { All patients } \\
(\mathrm{n}=156)\end{array}$ & $\mathrm{p}$ Value \\
\hline Mean (SD) age (years) & $51(13 \cdot 6)$ & $52(11 \cdot 7)$ & & 0.72 \\
\hline \multicolumn{5}{|l|}{ Sex: } \\
\hline Male & $20(28)$ & $12(14)$ & $32\}$ & \multirow{2}{*}{0.061} \\
\hline Female & $52(72)$ & $72(86)$ & $124\}$ & \\
\hline \multicolumn{5}{|l|}{ Marital status: } \\
\hline Single & $8(11)$ & $8(10)$ & 16 & \multirow{4}{*}{0.962} \\
\hline Married or cohabiting & $50(69)$ & $57(68)$ & 107 & \\
\hline Separated or divorced & $7(10)$ & $10(12)$ & $17\}$ & \\
\hline Widowed & $7(10)$ & $9(11)$ & 16) & \\
\hline \multicolumn{5}{|l|}{ Social class: ${ }^{\star}$} \\
\hline I & $8(13)$ & $12(15)$ & 20 & \multirow{5}{*}{$0 \cdot 35$} \\
\hline II & $13(20)$ & $24(31)$ & 37 & \\
\hline III & $24(38)$ & $19(24)$ & $43\}$ & \\
\hline IV/V & $3(5)$ & $7(9)$ & 10 & \\
\hline Retired & $16(25)$ & $16(21)$ & 32 & \\
\hline \multicolumn{5}{|l|}{ Type or site of cancer: } \\
\hline Breast & $37(51)$ & $45(54)$ & 82 & \multirow{9}{*}{$0.91 \dagger$} \\
\hline Lymphoma & $11(15)$ & $10(12)$ & 21 & \\
\hline Uterus, cervix, ovary & $6(8)$ & $13(15)$ & 19 & \\
\hline Bladder/prostate & $3(4)$ & $2(2)$ & 5 & \\
\hline Colorectal & 0 & $4(5)$ & 4\} & \\
\hline Head and neck, larynx & $4(6)$ & $5(6)$ & 9 & \\
\hline Sarcoma & $3(4)$ & $2(2)$ & 5 & \\
\hline Thyroid & $2(3)$ & 0 & 2 & \\
\hline Other & $6(8)$ & $3(4)$ & 9] & \\
\hline \multicolumn{5}{|l|}{ Disease stage: } \\
\hline Local only & $38(53)$ & $55(65)$ & 93) & \multirow{3}{*}{$0 \cdot 11$} \\
\hline Local or regional & $23(32)$ & $24(29)$ & $47\}$ & \\
\hline \multirow{2}{*}{\multicolumn{5}{|c|}{ Performance status $\left(\mathrm{WHO}^{17}\right): \ddagger$}} \\
\hline & & & & \\
\hline & $22(32)$ & $36(43)$ & 58 & \multirow[b]{3}{*}{$0 \cdot 28$} \\
\hline 1 & $31(45)$ & $34(41)$ & $65\}$ & \\
\hline 2 & $16(23)$ & $13(15)$ & 29] & \\
\hline
\end{tabular}

*Eight patients in therapy group and six in control group were unclassifiable or class not known.

$\dagger$ Breast cancer $v$ all others.
$\ddagger$ Performance status of three patients in therapy group and one in control group not known.

TABLE III - Scores at baseline of patients in trial of adjuvant psychological therapy

\begin{tabular}{|c|c|c|c|c|}
\hline \multirow[b]{2}{*}{ Questionnaire measure } & \multicolumn{2}{|c|}{ Therapy group } & \multicolumn{2}{|c|}{ Control group } \\
\hline & $\begin{array}{c}\text { No of } \\
\text { patients }\end{array}$ & $\begin{array}{l}\text { Mean }(\mathrm{SD}) \\
\text { score }\end{array}$ & $\begin{array}{c}\text { No of } \\
\text { patients }\end{array}$ & $\begin{array}{c}\text { Mean }(\mathrm{SD}) \\
\text { score }\end{array}$ \\
\hline \multicolumn{5}{|l|}{ Mental adjustment to cancer scale: } \\
\hline Fighting spirit & 71 & $47 \cdot 8(6 \cdot 0)$ & 83 & $47.8(6.6)$ \\
\hline Helplessness & 71 & $11 \cdot 2(3 \cdot 2)$ & 84 & $11 \cdot 3(3 \cdot 2)$ \\
\hline Anxious preoccupation & 71 & $23 \cdot 5(3 \cdot 2)$ & 83 & $23 \cdot 6(4 \cdot 3)$ \\
\hline Fatalism & 71 & $18.8(3.0)$ & 82 & $18.9(3.6)$ \\
\hline \multicolumn{5}{|c|}{ Hospital anxiety and depression scale: } \\
\hline Anxiety & 72 & $8.6(3.9)$ & 84 & $9 \cdot 2(4 \cdot 6)$ \\
\hline Depression & 72 & $6 \cdot 2(4 \cdot 0)$ & 84 & $5 \cdot 8(3.5)$ \\
\hline \multicolumn{5}{|l|}{ Rotterdam symptom checklist: } \\
\hline Psychological symptoms & 71 & $17 \cdot 3(4 \cdot 7)$ & 82 & $17 \cdot 6(5 \cdot 7)$ \\
\hline Physical symptoms & 70 & $30 \cdot 7(7 \cdot 4)$ & 82 & $31.0(8.0)$ \\
\hline \multicolumn{5}{|c|}{ Psychosocial adjustment to illness scale: } \\
\hline Total & 55 & $56 \cdot 9(10 \cdot 3)$ & 69 & $55 \cdot 9(10 \cdot 1)$ \\
\hline Health care orientation & 68 & $53 \cdot 5(10 \cdot 6)$ & 83 & $52.8(8.0)$ \\
\hline Vocational environment & 61 & $56.8(8.5)$ & 75 & $57 \cdot 3(8 \cdot 2)$ \\
\hline Domestic environment & 63 & $51.0(10 \cdot 8)$ & 76 & $49 \cdot 7(9 \cdot 7)$ \\
\hline Sexual relationships & 65 & $50 \cdot 9(11 \cdot 3)$ & 78 & $50 \cdot 4(10 \cdot 5)$ \\
\hline Extended family relationships & 67 & $55 \cdot 5(9 \cdot 1)$ & 81 & $58.0(8 \cdot 5)$ \\
\hline Social environment & 69 & $53 \cdot 8(11 \cdot 7)$ & 81 & $53.8(13.0)$ \\
\hline Psychological distress & 68 & $58 \cdot 8(10 \cdot 1)$ & 83 & $57 \cdot 2(11 \cdot 3)$ \\
\hline
\end{tabular}

men $(10 \% v 21 \% ; \mathrm{p}=0.055)$, a lower proportion in social classes I and II ( $16 \% v 37 \%$; trend test $\mathrm{p}=0.005)$, and lower scores on anxiety (mean $9.9 v 10.9$; $\mathrm{p}=0.048$ ), fighting spirit (mean 46.5 $v 49 \cdot 1 ; \mathrm{p}=0.002$ ), and anxious preoccupation (mean 22.5 v 24.3; $\mathrm{p}=0 \cdot 001)$.

\section{ADJUVANT PSYCHOLOGICAL THERAPY SESSIONS}

Although we planned to give weekly sessions of adjuvant psychological therapy over eight weeks, this was often not possible. Some patients could not attend regularly because of various exigencies-for example, severe physical symptoms due to advancing disease or chemotherapy. In the event, of 72 patients randomised to receive therapy, only $22(31 \%)$ had received six or more sessions by eight weeks and $19(26 \%)$ had received two or fewer. Twenty eight (39\%) patients received additional sessions between eight weeks and four months. The median number of sessions received up to four months was five (range 0-13).

Table II shows demographic and clinical charac- teristics including diagnosis, stage of disease, ${ }^{16}$ and performance status. ${ }^{17}$ Patients in the therapy and control groups were similar in all respects except that the therapy group contained a higher proportion of men $(28 \% v 14 \% ; \mathrm{p}=0.061)$. The numbers of patients taking antidepressant drugs in the therapy and control groups respectively were four and five at baseline, four and six at eight weeks, and four and 10 at four months of follow up. Therapy and control patients also had similar baseline scores for outcome measures (table III). Mean differences in scores from baseline to eight weeks and four months and the treatment effects are set out in table IV. At eight weeks the patients in the therapy group had significantly lower scores than controls on fighting spirit, helplessness, anxious preoccupation, and fatalism (mental adjustment to cancer scale), anxiety (hospital anxiety and depression scale); psychological symptoms (Rotterdam symptom checklist); and health care orientation on the psychosocial adjustment to illness scale (indicating a more positive adjustment to the disease and its treatment). At four months the treatment effect persisted in respect of anxiety (hospital anxiety and depression scale) and psychological symptoms (Rotterdam symptom checklist); in addition, patients who had received therapy reported significantly lower psychological distress on the psychosocial adjustment to illness scale than patients in the control group. With regard to depression, there were no significant differences in scores on the hospital anxiety and depression scale, but significant improvement associated with therapy was observed in two other subscales, the psychological subscale of the Rotterdam symptom checklist and the psychological distress subscale of the psychosocial adjustment to illness scale, which contain items on depression. Further analyses did not show any signifcant differences in the effect of adjuvant psychological therapy in subgroups defined by sex, age (above and below median), disease stage, and concurrent chemotherapy.

Changes in mean psychological scores are difficult to interpret in terms of clinical importance. We have therefore summarised our overall results in table V, which shows the proportion of patients at each stage of the trial who might be classified as suffering significant psychological dysfunction on the basis of three of the subscales we used. Theoretically, hospital anxiety and depression scale scores range from 0 to 21 for anxiety and depression: scores of $0-7$ indicate normal levels, 8-9 borderline, and 10-21 severe anxiety or depression (psychiatric disorder). In table $\mathrm{V}$ high scores for anxiety are defined as levels of $\geqslant 10$ (severe anxiety); for depression, high scores are defined as levels of $\geqslant 8$, indicating borderline and severe depression. Patients with high scores suffer from clinical anxiety or depression. Low fighting spirit and high helplessness scores ( $\leqslant 47$ and $\geqslant 12$, respectively, by our definition) indicate poor psychological adjustment to cancer.

The proportions of both therapy and control patients with clinical anxiety decreased sharply between screening and baseline assessments $(78 \%$ and $77 \%$ at screening $v 46 \%$ and $48 \%$ at baseline). This effect must be due in part to regression to the mean. A similar effect was not seen in depression or in fighting spirit and helplessness scores, which barely changed between screening and baseline assessments (table V). In each case, however, regression to the mean was evident among patients who were above the selection criteria. For example, of 43 patients whose screening depression scores were 8 or higher, 33 reduced their scores and only 10 increased their scores from screening to baseline.

Clinical anxiety - In the therapy group the proportion of severely anxious patients fell from $46 \%$ at baseline to $20 \%$ at eight weeks and $20 \%$ at four months; in the 


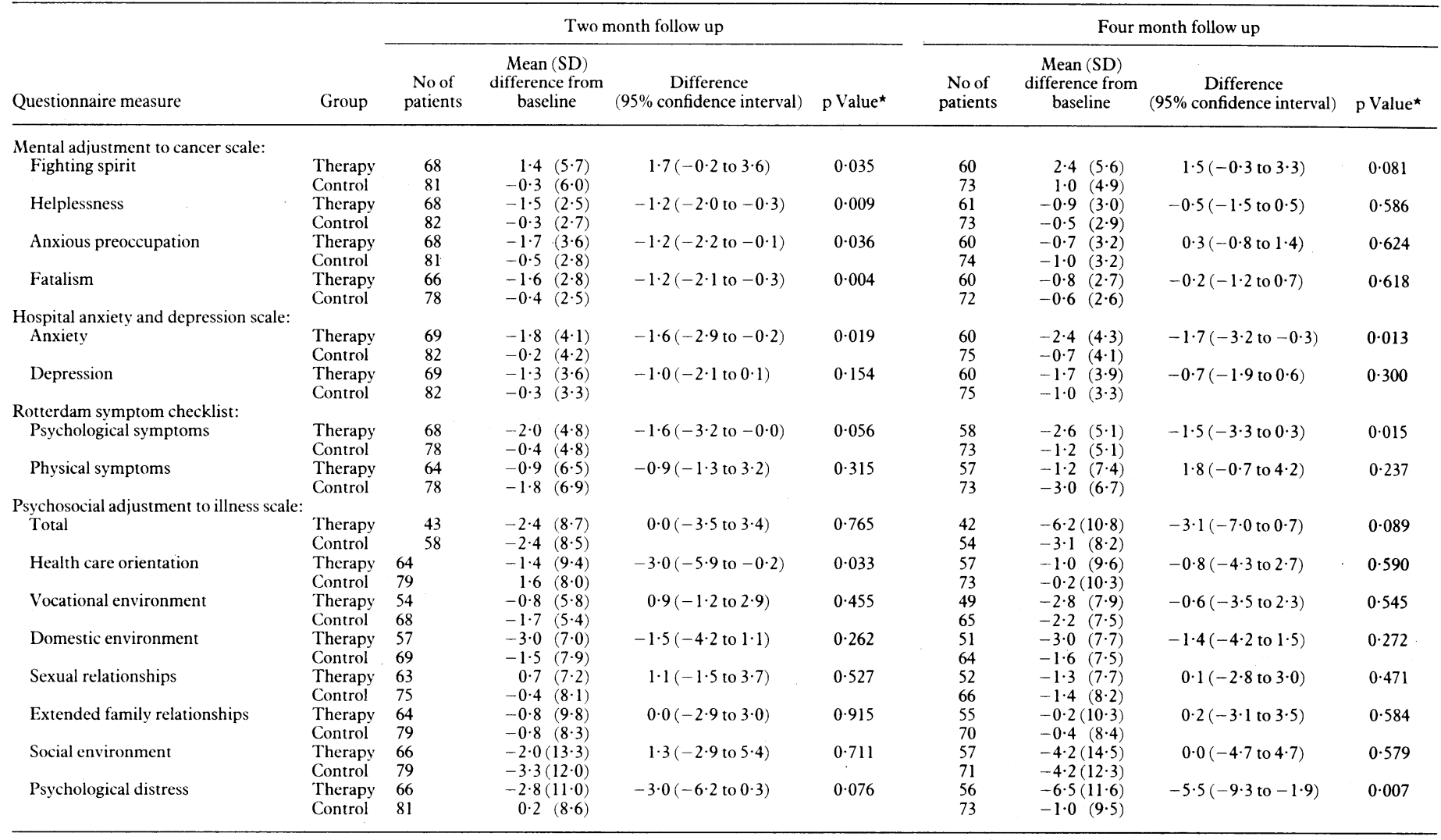

^Based on two sided non-parametric (Mann-Whitney) test; does not correspond exactly to $95 \%$ confidence interval based on $t$ distribution.

TABLE $\mathrm{v}-$ Clinical relevance of changes in scores on hospital anxiety and depression scale and mental adjustment to cancer scale. Values are numbers (percentages) of patients

\begin{tabular}{|c|c|c|c|c|c|c|c|c|}
\hline & \multicolumn{2}{|c|}{ Screening } & \multicolumn{2}{|c|}{ Baseline } & \multicolumn{2}{|c|}{8 Weeks } & \multicolumn{2}{|c|}{4 Months } \\
\hline & $\begin{array}{l}\text { Therapy } \\
\text { group } \\
(\mathbf{n}=72\end{array}$ & $\begin{array}{l}\text { Control } \\
\text { group } \\
(\mathrm{n}=84)\end{array}$ & $\begin{array}{l}\text { Therapy } \\
\text { group } \\
(\mathrm{n}=72)\end{array}$ & $\begin{array}{l}\text { Control } \\
\text { group } \\
(\mathrm{n}=84)\end{array}$ & $\begin{array}{l}\text { Therapy } \\
\text { group } \\
(\mathrm{n}=70)\end{array}$ & $\begin{array}{l}\text { Control } \\
\text { group } \\
(\mathrm{n}=83)\end{array}$ & $\begin{array}{l}\text { Therapy } \\
\text { group } \\
(\mathbf{n}=61)\end{array}$ & $\begin{array}{c}\text { Control } \\
\text { group } \\
(\mathbf{n}=76)\end{array}$ \\
\hline \multicolumn{9}{|l|}{ Anxiety (hospital anxiety and depression scale): } \\
\hline Normal $<8$ & $10(14)$ & $14(17)$ & $30(42)$ & $27(32)$ & $43(61)$ & $29(35)$ & $39(64)$ & $36(47)$ \\
\hline Borderline $8 \cdot 9$ & $6(8)$ & $5(6)$ & $9(13)$ & $17(20)$ & $12(17)$ & $19(23)$ & $9(15)$ & $7(9)$ \\
\hline Severe $\geqslant 10$ & $56(78)$ & $65(77)$ & $33(46)$ & $40(48)$ & $14(20)$ & $34(41)$ & $12(20)$ & $32(42)$ \\
\hline \multirow{2}{*}{\multicolumn{9}{|c|}{ Depression (hospital anxiety and depression scale): }} \\
\hline & & & & & & & & \\
\hline Normal $<8$ & $45(63)$ & $52(62)$ & $43(60)$ & $59(70)$ & $60(86)$ & $58(70)$ & $49(80)$ & $58(76)$ \\
\hline Borderline or severe $\geqslant 8$ & $27(38)$ & $32(38)$ & $29(40)$ & $25(30)$ & $9(13)$ & $24(29)$ & $11(18)$ & $17(22)$ \\
\hline Missing data & & & & & $1(1)$ & 1 (1) & $1(1)$ & $1(1)$ \\
\hline \multicolumn{9}{|c|}{ Fighting spirit and helplessness (mental adjustment to cancer scale): } \\
\hline Normal (fighting spirit $>47$, helplessness $<12$ ) & $47(65)$ & $55(65)$ & $49(68)$ & $52(62)$ & $58(83)$ & $49(59)$ & $47(77)$ & $48(63)$ \\
\hline Abnormal (fighting spirit $<47$, helplessness $\geqslant 12$ ) & $24(33)$ & $29(35)$ & $22(31)$ & $31(37)$ & $11(16)$ & $33(40)$ & $13(21)$ & $26(34)$ \\
\hline Missing data & $1(1)$ & & $1(1)$ & $1(1)$ & $1(1)$ & $1(1)$ & $1(1)$ & $2(3)$ \\
\hline
\end{tabular}

control group, there were only minor changes, from $48 \%$ at baseline to $41 \%$ at eight weeks and $43 \%$ at four months (table V).

Clinical depression-In the therapy group the proportion of depressed patients fell from $40 \%$ at baseline to $13 \%$ at eight weeks and $18 \%$ at four months; in the control group, there were only minor changes, from $30 \%$ at baseline to $29 \%$ at eight weeks and $23 \%$ at four months (table V).

Poor psychological adjustment to cancer-In the therapy group the proportion of patients with low fighting spirit and high helplessness scores fell from $31 \%$ at baseline to $16 \%$ at eight weeks and $22 \%$ at four months; by contrast, in the control group there was little change, the proportions being $37 \%$ at baseline, $40 \%$ at eight weeks, and $35 \%$ at four months (table V).

Included in the above figures are patients without clinical symptoms (low scorers) at baseline who developed such symptoms at eight weeks or four months of follow up; these comprised 25 patients (eight given therapy, 17 controls) scoring on anxiety,
22 (five given therapy, 17 controls) scoring on depression, and 28 (10 given therapy, 18 controls) scoring on fighting spirit or helplessness.

\section{Discussion}

Our aim was to conduct a rigorous, objective study. We therefore carried out a randomised controlled trial in which randomisation was performed independently. Although the need for randomisation is widely accepted, there may be a loophole when patients are randomised by the clinician, who may be tempted to interfere with randomisation on clinical grounds.

\section{POSSIBLE SOURCES OF BIAS}

A possible source of bias in the present study - the loss of 18 patients after randomisation - was examined. Only four of these patients refused to enter the study; the rest were lost for reasons unconnected with their allocated treatment. Moreover, comparisons between the baseline scores of the lost patients and those who remained in the trial showed no substantial differences. 
Hence it seems unlikely that the loss of these patients contributed substantially to the observed responses to treatment.

Patients who refused to enter the study before randomisation could not have biased the observed effects of therapy, but the high proportion of refusers requires comment. It was disappointing to find that, despite our best efforts, a third of the patients with high scores who were invited to enter the trial declined to do so. Even so, this figure is lower than that reported in an uncontrolled study of outpatients with high anxiety and depression scores mainly suffering from advanced cancers attending a London hospital. Those patients were offered group psychotherapy; $69 \%$ refused. ${ }^{18}$ An Israeli study of group therapy for mastectomy patients reported that nearly half the sample refused the offer of therapy. ${ }^{19}$ Much greater cooperation was obtained at another London hospital in a randomised trial of relaxation training for women with stage I and II breast cancer. who were receiving radiotherapy; only $12 \%$ refused..$^{20}$ The enviably low refusal rate may have been due to the fact that all patients offered relaxation training were also attending for radiotherapy, thereby enabling these women to regard relaxation training as an integral part of their physical treatment.

The highest refusal rate was obtained in a nonrandomised study. In our trial, randomisation rarely figured as a reason for refusal. Reasons commonly given by our patients were transport difficulties, long distance from hospital, fear of taking off too much time from work, and stoical attitudes such as "I'll try to manage on my own." Comparisons between those refusing and those taking part showed that although patients in each group were similar in many respects, refusers were older and of lower social class and had lower scores on anxiety, fighting spirit, and anxious preoccupation. Hence we urge caution in generalising from the present results to other populations of cancer patients. We are currently following up the refusers for 12 months to ascertain their psychological outcome.

\section{PSYCHOLOGICAL OUTCOME}

Patients in this trial were screened psychologically four to 12 weeks after primary diagnosis or first recurrence of cancer. By excluding acute stress reactions, which occur immediately after a diagnosis of cancer and commonly subside within a few weeks, we aimed to pick up patients with persisting psychological disorders related to cancer. By far the commonest symptoms were those of anxiety. Often the anxiety symptoms were accompanied by anxious preoccupation: these patients had recurring, intrusive thoughts about cancer and repeatedly checked their bodies (sometimes several times a day) for evidence of recurrence. Clinical depression was less common. The preponderance of clinical anxiety over depression among cancer patients has been reported by Sensky et al..$^{21}$ Based on the criteria stated earlier, $23 \%$ of an unselected sample of inpatients and outpatients at the Royal Marsden Hospital showed evidence of psychological morbidity. This figure compares favourably with that reported by Hughes, ' whose review of the literature concluded that a quarter to a half of inpatients receiving treatment for cancer suffer from anxiety or depression, or both, at any one time. The relatively low prevalence of psychological morbidity in the present sample may reflect less advanced disease; patients with a life expectancy of less than 12 months were excluded, and only $10 \%$ of our sample had metastatic disease. But we found no significant correlations between disease stage and any of the measures of psychological morbidity. A more likely explanation for the low prevalence of psychological disorder may lie in the fact that the Royal
Marsden Hospital is dedicated specifically to the care of cancer patients.

Except for health care orientation, social adjustment was not significantly improved by adjuvant psychological therapy. Possible explanations for this negative result are, firstly, that patients in both the therapy and control groups reported only minor disturbances in social adjustment, thereby creating a "floor effect," or, secondly, that our brief programme of adjuvant psychological therapy was insufficient to affect such complex areas as marital, sexual, and interpersonal relationships. Further investigations are required.

Patients receiving adjuvant psychological therapy showed significantly greater improvement than control patients on several measures of psychological outcome. Eight weeks after beginning therapy (when most patients had completed psychological treatment), treated patients reported significantly less anxiety (hospital anxiety and depression scale); helplessness, fatalism, and anxious preoccupation with cancer (mental adjustment to cancer scale); anxiety and depression (Rotterdam symptom checklist); and a more positive adjustment towards their disease and its treatment (psychosocial adjustment to illness scale). At four months, the significant improvement associated with adjuvant psychological therapy persisted in anxiety (hospital anxiety and depression scale) as well as anxiety and depression (Rotterdam symptom checklist); moreover, patients who had received the therapy experienced significantly less psychological distress (psychosocial adjustment to illness scale) than controls These statistically significant results were also clinically significant. During the course of the trial, a greater proportion of patients who received therapy moved out of the clinical range of scores than was the case among controls. We conclude that adjuvant psychologica therapy results in significant reduction in psychological morbidity related to cancer, with consequent improvement in the psychological dimension of the quality of life of cancer patients.

We record our deep gratitude to the late, greatly missed, Professor T J McElwain who invited us to conduct this trial a Royal Marsden Hospital and who consistently encouraged and supported us. We thank the Cancer Research Campaign for their generous funding of our group and the COMPAC' computer software which was used for data management. We also thank T Gladwell; our data manager; S Anderson, G Chesney, J Davidson, R Gardner, C Gorman, and H Saunders for their meticulous data collection and input; our consultan colleagues, who permitted access to their patients; and the patients, whose collaboration made this study possible and who taught us much.

1 Hughes JE. Psychological and social consequences of cancer. Cancer Suro 1987:6:455-75

2 Farash JL. Effect of counselling on resolution of loss and body image following a mastectomy. Dissertation Abstracts International 1979;39:4027 B

3 Maguire P. Tait A, Brooke M, Selwood R. Effect of counselling on the psychiatric morbidity associated with mastectomy. BMF 1980;281:1454-6. 4 Spiegel D, Bloom JR, Yalom I. Group support for patients with metastatic cancer. Arch Gen Psychiatry 1981;38:527-33.

Linn MW, Linn BS, Harris R. Effects of counselling for late stage canc patients. Cancer 1982;49:1048-55.

6 Telch CF, Telch MJ. Group coping skills instruction and supportive group therapy for cancer patients: a comparison of strategies. $\mathcal{F}$ Consult C/lin Psychol $1986 ; 54: 802-8$

Cain EN, Kohorn EI, Quinlan DM, Latimer K, Schwartz PE. Psychosocia benefits of a cancer support group. Cancer 1986;57:183-9.

8 Bridge LR, Benson P, Pietroni PC, Priest RG. Relaxation and imagery in the treatment of breast cancer. BM7 1988:297:1169-72.

9 Watson $M$, Denton S, Baum $M$, Greer S. Counselling breast cancer patients: specialist nurse service. Counselling Psychology Quarterly 1988;1:25-34.

10 Zigmond A, Snaith RP. The hospital anxiety and depression scale. Acta Psychiatr Scand 1983;67:361-70.

Acta Psychar Scand $1983,67:$ prognostic significance. Cancer Surv 1987;6:439-53.

12 Watson M, Greer S, Young J, Inayat Q, Burgess C, Robertson B. Development Watson $M$, Greer $S$, Young J, Inayat $Q$, Burgess $C$, Robertson $B$. Development
of a questionnaire measure of adjustment to cancer-the MAC scale. Psychol Med 1988;18:203-9.

13 Derogatis LR. Psychosocial adjustment to illness scale (PAIS). Baltimore: Clinical Psychometric Research, 1983.

14 De Haes JCJM, van Knippenberg FCE, Neijt JP. Measuring psychologica 
and physical distress in cancer patients: structure and application of the Rotterdam symptom checklist. Br f Cancer 1990;62:1034-8.

15 Moorey S, Greer S. Psychological therapy for patients with cancer. Oxford: Heinemann Medical Books, 1989.

16 Greer S, Moorey S, Baruch J. Evaluation of adjuvant psychological therapy for clinically referred cancer patients. Br f Cancer 1991;63:257-60.

17 World Health Organisation. WHO handbook for reporting results of cancer treatment. Geneva: WHO, 1979.

18 Ford MF, Jones M, Scannel T, Powell A, Coombes RC, Evans C. Is group psychotherapy feasible for oncology out-patients attenders selected on the basis of psychological morbidity? Br $\mathcal{F}$ Cancer 1990;62:624-6.
19 Baider L, Amikan JC, Kaplan De-Nour A. Time-limited thematic group with post mastectomy patients. F Psychosom Res 1984;28:323-30.

20 Bridge LR, Benson P, Pietroni PC, Priest RG. Relaxation and imagery in the treatment of breast cancer. BMF 1988;297:1169-72.

21 Sensky T, Denehy M, Gilbert A, Begent R, Newlands E, Rustin G, et al. Physicians' perceptions of anxiety and depression among their out-patients: relationships with patients' and doctors'; satisfaction with their interview. f R Coll Physicians Lond 1989;1:33-8.

(Accepted 16 December 1991)

\title{
Public opinion and purchasing
}

\author{
Andrew Richardson, Mark Charny, Stuart Hanmer-Lloyd
}

\begin{abstract}
Objectives-To explore the use of a questionnaire to obtain representative public opinions on health services. To examine residents' priorities, knowledge, and views on the public's role in decision making.
\end{abstract}

Design-Self administered postal questionnaire.

Population-Random sample of 1500 residents in Bath District Health Authority, drawn from electoral registers.

Main outcome measures-Levels of agreement or disagreement with statements provided and degree of importance given to services and aspects of services.

Results -70 questionnaires were returned unopened. Completed questionnaires were returned by $704(49.2 \%)$ of the 1430 remaining residents. Kidney dialysis was thought very important by $559(87 \%)$ respondents and family planning by only $58(9 \%)$. Public priorities did not seem to reflect value for money. Clear information about treatment was rated as very important by $530(76 \%)$ and comfortable waiting areas by $70(10 \%) .372(53 \%)$ of respondents said that they would definitely travel to a hospital outside the district to reduce their wait for surgery. Knowledge of the services provided by the authority and the money available to it was poor. $446(65 \%)$ respondents wanted greater public involvement in decision making.

Conclusions - A postal questionnaire can provide useful information about public priorities and perceptions about the services provided. More information about health services and their costs and benefits should be given to the public to assist greater public participation in decision making.

\section{Introduction}

Health authorities need to take the views of con-

Public Health Directorate, Bath Health Authority, Bath BA1 3QE Andrew Richardson, $\mathrm{MB}$, senior registrar in public health medicine

Mark Charny, PHD, director of public health

Bristol Business School, Bristol Polytechnic, Bristol BS16 1QY

Stuart Hanmer-Lloyd, PHD, senior lecturer

Correspondence to:

Dr Richardson.

BMF 1992;304:680-2 sumers into account when deciding what volume and type of services to buy. In making referrals to secondary care general practitioners act as consumers. Surveys of their opinions have been reported.' We tested the ability of a questionnaire survey to obtain representative public opinions. Surveys of public opinion are distinct from those of patient satisfaction (box), which are more commonly undertaken.

\section{Subjects and methods}

We prepared a questionnaire containing 44 questions. Most of the questions gave respondents a statement or suggestion and asked them to indicate their opinion or agreement on a Likert-type scale of five options. ${ }^{2}$ Questions asked about the importance of selected services, knowledge of the health authority, and the role of the public in decision making.
Characteristics of patient satisfaction and public opinion surveys

Patient satisfaction surveys

- Study population is patients or service users

- Seek direct experience of services

- Help providers to improve service quality

- Are retrospective

Public opinion surveys

- Study population is the resident population

- Seeks views of needs and priorities

- Help district health authorities to make purchasing decisions

- Are prospective

A sample of 1500 residents was drawn systematically from the electoral registers of parishes within the health authority boundary. A single mailing was made in November 1990. Reply paid envelopes were provided.

No repeat mailing was done as we decided that allowing respondents complete anonymity was more important than any increase in response from a reminder mailing. Inducements, common in market research, ${ }^{3}$ were not used as they may not increase response rates in health studies ${ }^{4}$ and could be contentious in the current political and social environment within the NHS. Data were analysed with the statistical package for the social sciences (SPSS-PC). ${ }^{5}$

\section{Results}

Seventy questionnaires were returned unopened, mainly because the addressee was no longer living at that residence. Of the remaining 1430 questionnaires, $704(49 \cdot 2 \%)$ were returned. The age and sex distribution of the respondents did not differ significantly from that of the district population as a whole.

People were asked how important they believed a selection of 10 services were. Table I shows these

TABLE I-Proportion of respondents who thought services very important

\begin{tabular}{lc}
\hline Service & $\begin{array}{c}\text { No }(\%) \text { of } \\
\text { respondents } \\
(\mathrm{n}=690)\end{array}$ \\
\hline Kidney dialysis & $559 / 687(81)$ \\
Special care baby unit & $483 / 680(71)$ \\
Vaccinations & $474 / 689(69)$ \\
Hip replacements & $314 / 693(45)$ \\
Long stay geriatric care & $241 / 689(35)$ \\
School medical service & $225 / 687(33)$ \\
Day hospitals & $178 / 685(26)$ \\
Family planning & $160 / 682(23)$ \\
Help for those who want to stop smoking & $58 / 686(8)$ \\
Varicose vein surgery & $30 / 680(4)$ \\
\hline
\end{tabular}

